Angelika Corbineau-Hoffmann

Paradoxie der Fiktion 


\title{
Komparatistische Studien
}

\author{
Beihefte zu „arcadia“ \\ Zeitschrift für Vergleichende Literaturwissenschaft
}

Herausgegeben von

Maria Moog-Grünewald und Jürgen Wertheimer

Band 17

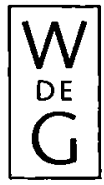

Walter de Gruyter · Berlin · New York

1993 


\title{
Paradoxie der Fiktion Literarische Venedig-Bilder 1797-1984
}

\author{
von \\ Angelika Corbineau-Hoffmann
}

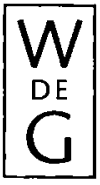

Walter de Gruyter · Berlin · New York 1993 
Als Habilitationsschrift auf Empfehlung des Fachbereichs 13,

Philologie I, der Johannes Gutenberg-Universität in Mainz gedruckt mit Unterstützung der Deutschen Forschungsgemeinschaft

(Gedruckt auf säurefreiem Papier, das die US-ANSI-Norm über Haltbarkeit erfüllt

Die Deutsche Bibliothek - CIP-Einheitsaufnabme

Corbineau-Hoffmann, Angelika:

Paradoxie der Fiktion : literarische Venedig-Bilder 1797-1984/ von Angelika Corbineau-Hoffmann. - Berlin ; New York : de Gruyter, 1993

(Komparatistische Studien ; Bd. 17)

Zugl.: Mainz, Univ., Habil.-Schr., 1990

ISBN 3-11-012937-X

NE: GT

(C) Copyright 1993 by Walter de Gruyter \& Co., D-1000 Berlin 30

Dieses Werk einschließlich aller seiner Teile ist urheberrechtlich geschützt. Jede Verwertung außerhalb der engen Grenzen des Urheberrechtsgesetzes ist ohne Zustimmung des Verlages unzulässig und strafbar. Das gilt insbesondere für Vervielfältigungen, Übersetzungen, Mikroverfilmungen und die Einspeicherung und Verarbeitung in elektronischen Systemen.

Printed in Germany

Umschlagillustration: Ludovico DeLuigi, La Gigantessa

Umschlaggestaltung: Rudolf Hübler

Satz und Druck: Arthur Collignon $\mathrm{GmbH}$, Berlin

Bindearbeiten: Lüderitz \& Bauer-GmbH, Berlin 
Jenes unrealste aller Reiche, unheimlichste aller Phantasmata, die sogenannte Wirklichkeit ...

Hugo von Hofmannsthal 



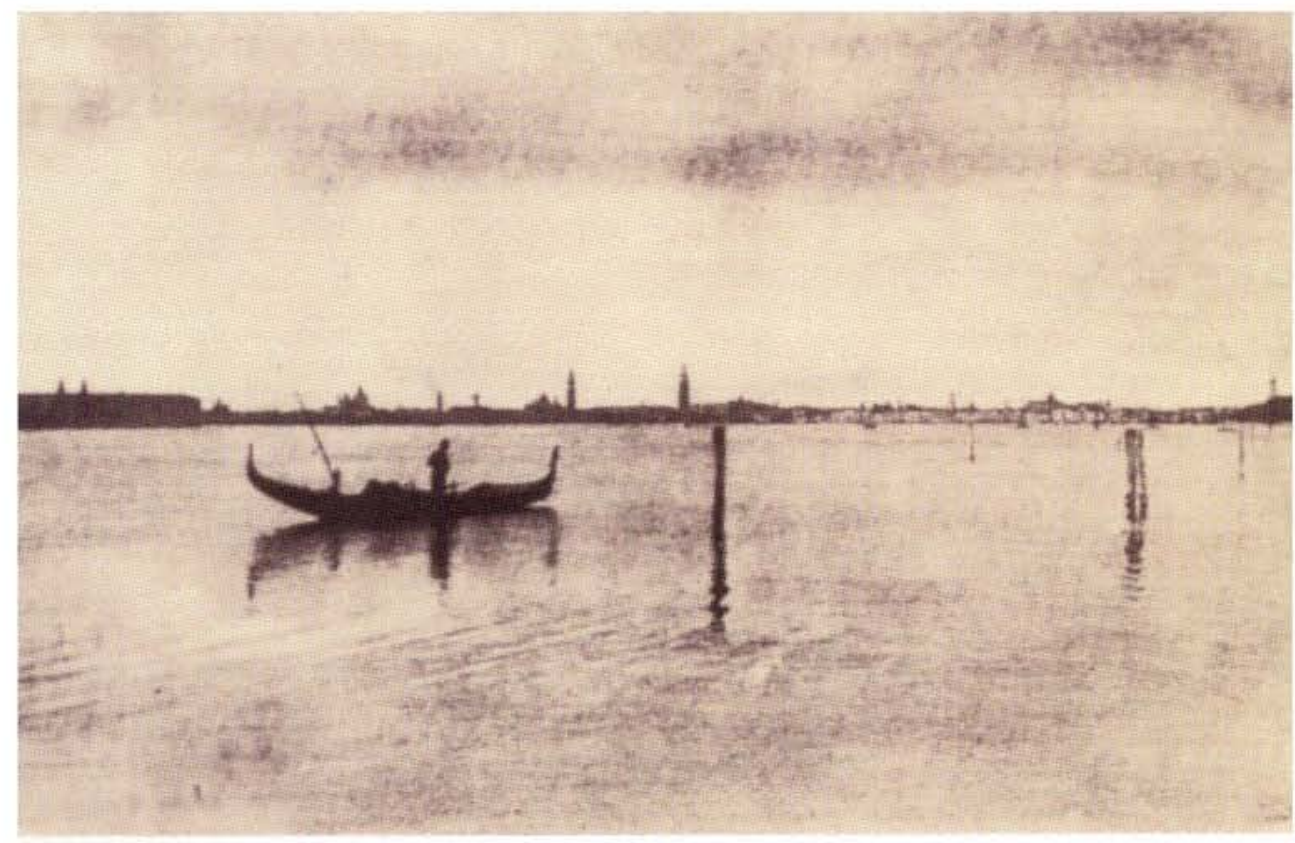

J. Craig Annan, Venedig, vom Lido aus gesehen.

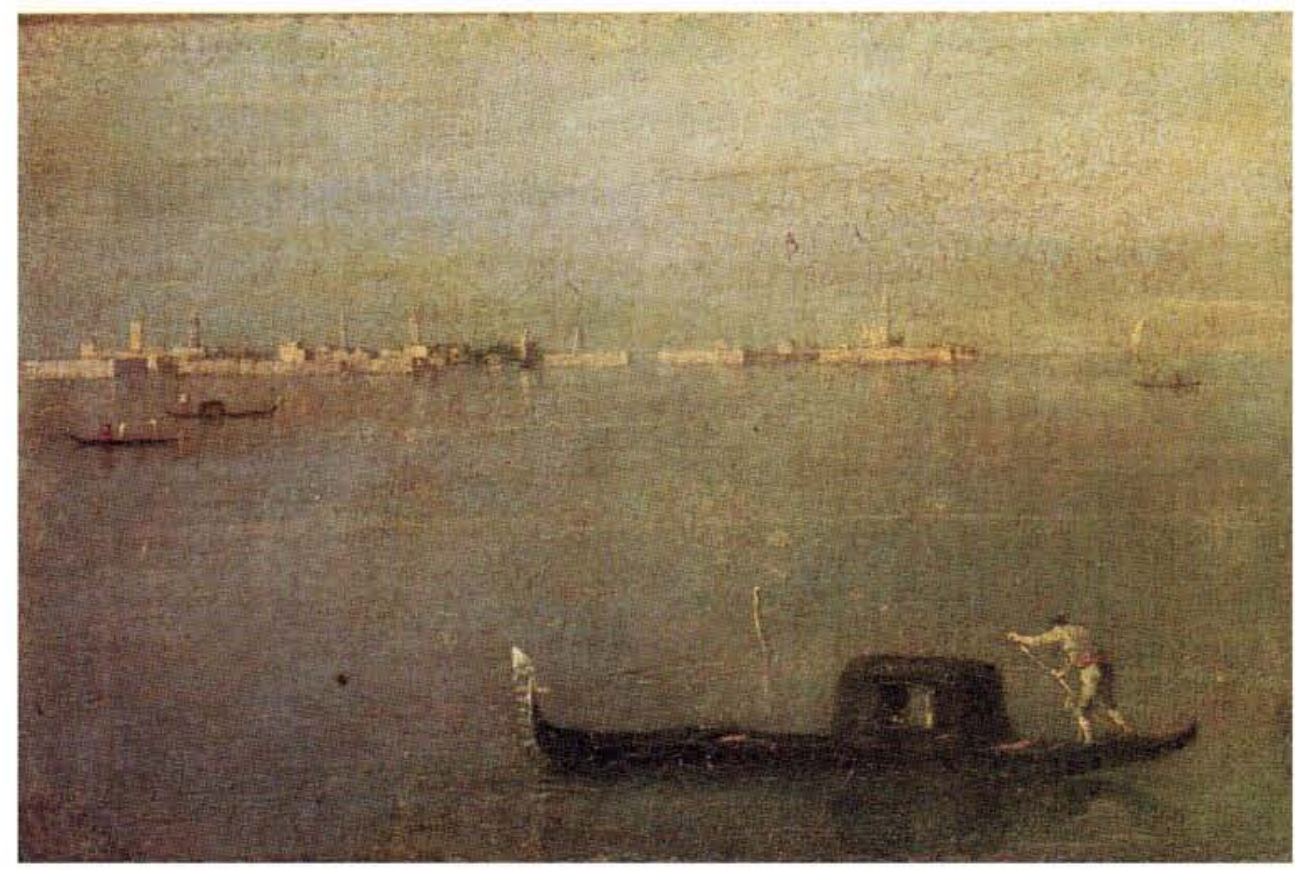

Francesco Guardi, Laguna grigia (Gondole sulla Laguna). 
